\title{
POESIA, HISTÓRIA E RAZÃO CRÍTICA: DE ITABIRA PARA O VASTO MUNDO
}

\begin{abstract}
Marlise Sapiecinski
RESUMO: Dans l'ouvre de Carlos Drummond de Andrade, poésie, histoire et raison critique s'entremêlent et donnent le ton d'une lyrique profondément refléchie, qui, à ses meilleurs moments, comme c'est le cas dans Claro Enigma (1951), a atteint l'union harmonieuse entre la raison et la sensibilité. Comme le savait déjà Aristote, l'intuition poétique, bien qu'elle corresponde à un mode sui generis d'appréhension du monde - qui exige, évidemment, une attitude qui ne peut être à peine intellectuelle -, ne répond pas à une modèle d'habilité étrangère à l'homme - d'inspiration divine, comme disait Platon, non sans ironie - mais comprend sa dose particulière de raison en agissant conformément à la sensation. Toutes les deux reposent, par conséquent, sur une base à la fois affective et intellectuelle. Irrémédiablement seul, et en même temp solidaire de toutes les créatures, toujours réticente par rapport à la communicabilité de l'expérience poétique: voici le grand conflit réfléchit dans tout son art. C'est dans ce conflit que s'instaure et s'étend, de différentes manières, dans toute sa trajectoire, le profond "sentiment social" de sa poésie.
\end{abstract}

PALAVRAS-CHAVE: Poesia Moderna Brasileira, Drummond, Claro Enigma, Lírica, Razão,História, Crítica.

"É a minha própria vida que se
espanta, e é ela que deve me for-
necer, se puder, minhas respostas,
pois é somente nas reações de nos-
sa vida que pode residir toda a for-
ça e como que a necessidade de
nossa verdade."

Valèry

Certa ocasião Mário de Andrade surpreendeu o amigo Paulo Mendes Campos ao confessar que era melhor poeta do que os outros geralmente pensavam, sobre-

Marlise Sapiecinski é doutoranda em Literatura Brasileira / UFRGS. 
tudo os escritores que elogiavam muito nele o prosador e o ensaísta. Em seguida, conta-nos Paulo Mendes Campos, Mário suspirou, aquele suspiro longo, brasileiramente conformado, e concluiu: Mas é claro que estou muito longe de ser um poeta tão bom feito o Carlos e o Bandeira (CAMPOS, 1987, p.2).

A impressão de Mário, tratando-se aqui da poesia de Carlos Drummond de Andrade, a quem o autor de Macunaíma costumava chamar de demônio da inteligência, é reveladora, já nas primeiras décadas do século, do sentimento quase unânime que Drummond despertaria na mentalidade coletiva nacional. Poeta de singular agudeza de sentimentos, soube, como poucos, comover pela simplicidade e transmitir aquele sentimento universal, imprescindível a grande literatura, de que nos fala Antonio Candido, sem precisar se afastar dos valores locais, a ponto de transformar a sua querida e doída Itabira, na cidade natal de todos os que carregam no peito a mágoa e o orgulho da província onde nasceram. É através do próprio espanto diante da vida que desperta nossa memória individual. Por essas razões é que o fato de tantas e repetidas vezes ter cantado sua terra está longe de ser suficiente para que lhe seja outorgado o rótulo de poeta nacionalista. Falar da terra é apenas um pretexto para falar do homem, pois é o sentimento humano que lhe interessa acima de tudo.

Mas não é só isso que o diferencia e faz dele nosso Poeta Maior, e sim a sensibilidade histórica e crítica com que envolveu esse sentimento humano que se impõe em seus versos transformando-o num pintor de terras e gentes, fazendo do menino antigo, do cidadão itabirano, um cidadão do mundo. É por isso que poesia, história e razão crítica nele se entrelaçam e dão a tônica de sua lírica. Uma lírica que em seus melhores momentos, como é o caso de Claro Enigma (1951), atingiu a união harmônica entre razão e sensibilidade, a mediação perfeita entre linguagem e emoção criadora. Pois é sobre este livro em particular que se pretende dizer algumas palavras, tentando cumprir a difícil tarefa de concentrar no curto espaço deste texto o que, certamente, corresponde ao que de mais alto nível poético se pode encontrar no cenário da poesia brasileira. Versos que, sem dúvida, podem figurar, conscientes de sua grandeza, ao lado dos melhores de Baudelaire, Rilke, Rimbaud, Eliot, Mallarmé, Valèry, Pessoa, Neruda ou Lorca, para citar apenas os que primeiro foram lembrados.

Em primeiro lugar, não dá para deixar de perceber o interesse e a surpresa que um livro como Claro Enigma provoca, mesmo entre aqueles que sempre acompanharam de perto a evolução poética de Carlos Drummond de Andrade. Aos que valorizaram sobretudo o que se costumou chamar de poesia social de um livro como $A$ Rosa do Povo (1945), imediatamente anterior, por vezes esquecendo ou ignorando a rara densidade de pensamento que envolve esses poemas socialmente engajados, a nova postura assumida diante do ato criativo, num momento de aparente descaso pelos acontecimentos presentes, não deixou de causar estranheza. Não foi sem razão, portanto, que os versos de Claro Enigma muitas vezes receberam os nem sempre justificados e algumas vezes absurdos adjetivos de alienados, herméticos ou metafísicos, ou então, como querem os mais radicais, saudosos do Drummond participativo, uma ligeira pausa na evolução da poesia drummondiana. Pausa a que 
Haroldo de Campos chamou de estação neoclassizante. ${ }^{1}$ Isso quando não costumam confundir a originalidade e a profundidade intelectual de seu "classicismo", identificando-o com os princípios da geração de 45 , estilisticamente reacionários, como o fez Gilberto Mendonça Teles (1970, p.22). Por seu turno, Emanuel de Moraes não hesitou em afirmar que o verso de Drummond perdeu o encanto porque ficou encasulado pelo formalismo métrico (1977, p.115). E é Álvaro Lins quem completa dizendo que o soneto não é uma forma de expressão adequada a Drummond (1963, p.23). (!)

Concepções dessa ordem levaram alguns críticos a afirmar que os poemas de Claro Enigma parecem se afastar daquela atitude crítica perante a existência e a própria possibilidade do fazer artístico que até então marcara a trajetória do poeta, o que talvez explique a sua resistência em refletir com maior interesse sobre uma obra que, para outros, menos numerosos é certo, representa o verdadeiro amadurecimento do poeta de Itabira, do poeta brasileiro, do poeta mais do que nunca universal, mais próximo da essência do homem, da natureza da lírica, da alma da poesia.

Entre esse últimos, que perceberam o alto valor da poesia da fase de Claro Enigma, está o nome de José Guilherme Merquior, que, na maioria das vezes, soube fazer da crítica de poesia brasileira um ato de inteligência e lucidez. Contrariando um certo tipo de crítica, que desconhece os princípios estéticos da arte e despreza o pensamento sistemático, a fundamentação filosófica, Merquior sentencia: é preciso que a crítica se faça razão e pela razão compreenda a obra (1996, p.187). E percebendo também que todo o ato de compreensão se baseia em elementos racionais é que defende o lugar do intelecto e da razão no nível mais alto do lirismo, pois é com a razão e pela razão, diz ele, que se faz da poesia um ato de compreensão do mundo, de domínio do homem, pela incansável fundação de novos significados (Ibid., p. 226), ${ }^{2}$ uma vez que a poesia é e deve ser a recusa do insignificante, do que não faz sentido, e aqui penetramos o mais intimo foro da sua racionalidade (Ibid., p.201).

Olhando a poesia de Drummond desse ângulo é que se pode afirmar que a linguagem poética duramente lapidada no curso de sua obra, com disciplina e sensibilidade, não deixa de apresentar em Claro Enigma aquela insuperada relação do indivíduo com o universo, nas suas múltiplas tentativas de explicação e de interpretação do ser e do estar no mundo, como ele mesmo se referiu, e que num poema como "A máquina do mundo" atinge o ponto mais complexo: a recusa do conhecimento absoluto, outrora razão da caminhada de quem sempre quis penetrar o sentido íntimo das coisas. O antigo movimento de procura, tantas vezes frustrado, provoca um desen-

${ }^{1}$ Cf. CAMPOS, 1992. A denominação de estação neoclassizante refere-se obviamente a uma certa incorporação dos recursos da lírica tradicional, que é significativa neste período, como a métrica e a rima e, sobretudo, a presença do soneto. De acordo com José Guilherme Merquior, a incompreensão sectária [de Haroldo de Campos] diante do estilo clássico de Claro Enigma sugere um certo anexionismo da parte do teorizador concretista em relação ao grande lírico brasileiro. (Cf. Verso Universo em Drummond, 1975, p.200)

${ }^{2}$ Concebendo a razão como princípio essencial para se considerar o mundo como algo inteligível, então, conclui Merquior, se a lírica é, realmente, significativa, deve conter razão. 
canto voraz, que anula o desejo de apreender essa total explicação da vida, tardiamente oferecida a esse alguém, noturno e miserável, em quem a fé se abrandara, e mesmo o anseio,/ a esperança mais mínima(...) de ver desvanecida a treva espessa, dissolve-se. O desdobramento dramático dessa luta fáustica, de certo modo, sintetiza o estado de ânimo que ilumina (e, num certo sentido, "escurece") a poesia de Claro Enigma:

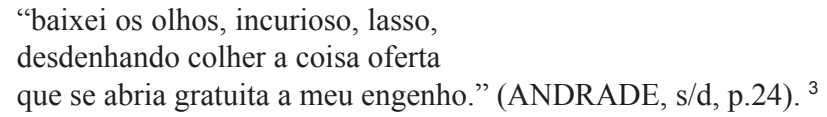

Aquela ironia corrosiva, de que fala Luiz Costa Lima, que marca profundamente a produção anterior, parece se dissolver em composições que irão impor um novo ritmo à poética drummondiana. Não é sem razão que a linguagem assume agora um tom mais sóbrio, mais contido. A presença do soneto não deixa despercebido um certo aprimoramento formal, o que não quer dizer que Drummond tenha abandonado completamente a ironia, esse movimento ao canto da boca, cheio de mistérios, feição própria dos céticos e desabusados (MACHADO DE ASSIS, s/d, p. 93), como a seu próprio modo definiu Machado de Assis. Não, a ironia apenas mudou de face, se assim se pode dizer, deixa de ser princípio operativo para ser ponto de partida, que o poema pressupõe (LIMA, 1968, p. 197). À irreverência poética dos anos 30 sucede um tom de sóbria dignidade, que parece antes desprovido de espanto do que definitivamente desencantado.

Recusando-se ao papel de poeta-profeta, como muitos gostariam de vê-lo representar, e sobretudo ao de mártir do tempo de meus ombros suportam o mundo, já não lhe interessa deixar explícita nenhuma mensagem aos homens de seu tempo, talvez cônscio da inutilidade presente de seus versos. É assim que já no poema de abertura - "Dissolução"- de braços cruzados, como que resignado, o poeta apenas aceita que brote/ uma outra ordem de seres/ e coisas não figuradas, aparentemente alheio a tudo o que diz respeito à realidade ou exija ação imediata:

"escurece, e não me seduz

tatear sequer uma lâmpada.

Pois que aprouve ao dia findar, aceito a noite." (p. 15)

Há dois aspectos que marcam esse período e que parecem ter influenciado decisivamente essa fase da produção drummondiana. O primeiro é o momento social de pós-guerra, que revogou quase tudo a um ritmo de espera e a um certo tédio pelos acontecimentos presentes. Nesse sentido, a epígrafe de Claro Enigma - Les événements m'ennuient - buscada em Valéry, é bastante significativa. O segundo é um certo esgarçamento da linguagem modernista, que para muitos, nessa altura, parecia ter se perdido na busca incansável de novas formas de representação, exagerando algumas vezes na liberdade de criação e na despreocupação formal que as conquistas iniciais do movimento de 22 tornaram possíveis. O que Drummond parece, na verdade, recu-

${ }^{3}$ Os demais poemas citados, do livro Claro Enigma, referem-se a essa edição. 
perar é aquela consciência artesanal do fazer artístico, que para alguns significou, equivocadamente, um tributo à tradição, mesmo porque, a excelência de seus versos não se deve, de maneira alguma, simplesmente a um certo retorno às formas de composição tradicionais, ainda que seja significativa a presença do soneto, o recurso à métrica e à rima, mas sim à capacidade de se utilizar das formas clássicas da lírica sem deixar de ser absolutamente moderno.

Mas ao poeta, nesse momento, questões dessa natureza pouco parecem importar. Com o firme propósito de mergulhar fundo na essência mesmo das coisas e se deter menos na aparência imediata, ele se deixa ficar como um espectador que não se quer notado: E nem destaco minha pele/ da confluente escuridão ("Dissolução"). É nesse mesmo poema que aparece também uma certa desconfiança ou um desprezo até pelo ato de criar. Desprezo que se manifestará em outros momentos do livro, sugerindo que é hora de se calar. Numa espécie de inversão de sentido, é a alma angustiada que agora parece pesar mais do que o próprio corpo:

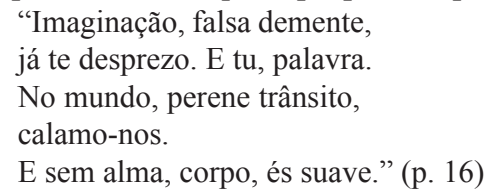

Nessa fase de introspecção, as formas fixas parecem adaptar-se melhor ao estado de alma do poeta. Nesse sentido, é que Hegel insiste na união harmônica entre o conteúdo e a forma, pois de outra maneira a arte não atinge o ideal, e o ideal exige é que a forma exterior seja a expressão da alma (HEGEL, 1996, p. 186). Por sua vez, a forma exterior exige uma atividade subjetiva criadora capaz de despertar a sensibilidade alheia, isto quer dizer que, forma e conteúdo são, em relação ao ideal, substancialmente dependentes, o que dificilmente se colocaria como um problema para um homem do gênio poético de Carlos Drummond de Andrade. Eternamente comovido com a humanidade, mesmo quando parece desinteressar-se dela, ele não deixa de provocar os mais difusos sentimentos, principalmente naqueles momentos em que seus versos hão de inquietar, pois seu soneto já não compactua com uma poesia que quer servir de consolo. Ao contrário:

"Quero que meu soneto, no futuro,

não desperte em ninguém nenhum prazer.

E que, no seu maligno ar imaturo,

ao mesmo tempo saiba ser, não ser.

Esse meu verbo antipático e impuro

há de pungir, há de fazer sofrer,

tendão de Vênus sob o pedicuro."

(“Oficina Irritada”, p. 42)

Eis um bom exemplo da modernidade crítica do soneto drummondiano. É essa postura que torna inadmissível pensar que o poeta de Claro Enigma estava atacado da mesma nostalgia da restauração que marcou profundamente toda uma geração 
(a de 45) que lhe foi contemporânea, pois se parecem coincidir num certo aprimoramento formal, distinguem-se completamente quanto ao conteúdo e a forma de enfrentamento da palavra. Além do mais, Drummond sempre foi contrário a qualquer tipo de classificação acadêmica. Se optou pelas formas metrificadas foi porque estas correspondiam, naquele momento, ao seu mais íntimo desejo de expressão, pois da linguagem sempre procurou extrair o máximo sentido: se insistiu em transformá-la em enigma, um claro enigma, aliás, foi para que dela o leitor extraísse o máximo de significação. Ele sabia muito bem do que uma palavra é capaz, de que forma um claro enigma se deixa surpreender ("Oficina Irritada").

De um modo geral, no entanto, o que caracteriza toda sua produção poética é, sem dúvida, como observou Afonso Arinos, já em 1944, numa linha de pensamento que se aproxima da de José Guilherme Merquior, o predomínio visível dos seus atributos intelectuais sobre todos os outros. A agudíssima inteligência deste poeta exerce as principais funções, nos seus versos (FRANCO, 1977, p.83). O seu domínio total da língua, apontado por Afonso Arinos no mesmo artigo, não apenas se confirmou nas produções posteriores, como se destacou em Claro Enigma. É importante novamente ressaltar o sentido que a palavra adquiria para quem buscava cotidianamente a linguagem mais simples (o que nem sempre quer dizer a linguagem mais fácil) na luta pela imagem perfeita. Em Drummond nada, absolutamente nada, é dito por acaso, pois até o acaso é preenchido de significação. Por tudo isso, erra de longe aquele que vê em Claro Enigma antes de tudo um conjunto fechado de poemas metafisicos, alheios ao estar no mundo e realmente despreocupados com o rumo dos acontecimentos. Seu modo de fazer artístico, atento e seguro, inesperadamente preocupado com a forma, não se furta, contudo, àquela comoção perene, quase indignada diante do mundo, que em "Cantiga de Enganar" declara: O mundo não vale o mundo,/ meu bem.

É essa mesma postura e voz inconfundível que se ouve em toda a trajetória desse poeta desejoso de um canto maior: Triste é não ter um verso maior que os literários, declara ele em "Contemplação no Banco". Terminada a guerra, o mundo, também ao poeta, parecia sem sentido: $O$ mundo não tem sentido, diz ele em "Legado", esses monstros atuais, não os cativa Orfeu. Mas mesmo diante de tanta descrença e desencanto no poder da canção ainda é possível ouvir o eco de uma voz que no fundo continua a acreditar que talvez se encontre na palavra, na poesia, a possibilidade de redenção: Meu bem, usemos palavras./ Façamos mundos: idéias./ Deixemos o mundo aos outros, / já que o querem gastar.

É preciso usar a palavra que salva. Aos outros, ensurdecidos pelo ruído das máquinas que garantem o desenvolvimento de sua ciência, da qual se tornaram meras cópias reprodutoras, que fique o mundo destruído pelo sofrimento e pela brutalidade dos valores que elegeram como fundamentais. É preciso encontrar um novo lugar para a poesia, antes que se perca de vez a capacidade de ouvir as canções de timbre mais comovido. Apesar de compreender a importância social do papel que desempenha, do sentimento agudo do relativo, de que a nada se pode outorgar a condição de 
absoluto, afloram infinitas incertezas e outras tantas desconfianças, seja em relação à incomunicabilidade da própria poesia - e nada resta mesmo do que escreves - seja em relação à experiência amorosa, familiar ou histórica, o que leva o poeta a questionar a validade do que escreve:

"Que lembrança darei ao país que me deu

tudo o que lembro e sei, tudo quanto senti?

Na noite do sem-fim, breve o tempo esqueceu

minha incerta medalha, e a meu nome se ri.

(...)

De tudo quanto foi meu passo caprichoso

na vida, restará, pois o resto se esfuma,

uma pedra que havia no meio do caminho."

("Legado", p.19)

Esse poema é bastante significativo, pois reflete a consciência da vacuidade da busca e a contemplação cética do passado, e reafirma também a velha inquietação em forma de desconforto (uma pedra que havia em meio do caminho). E como já havia anunciado em "Oficina Irritada", só que agora quase em forma de um lamento, retoma a idéia de que seus versos já não servem nem mesmo para consolo:

"Não deixarei de mim nenhum canto radioso, uma voz matinal palpitando na bruma

e que arranque de alguém seu mais secreto espinho. (p. 19)

Ainda que trilhe um caminho oposto ao do poeta-profeta e mesmo que, nessa fase, possa enganosamente parecer menos comprometido com a prosa da vida, não significa que seus versos ficaram mais pobres de significação, ao contrário, pois, na verdadeira poesia, a mensagem ideológica implica a superação do caráter ideológico. Além do mais, numa época de incertezas, seria até ingênuo pensar que um homem da personalidade poética de Carlos Drummond de Andrade pudesse realmente ignorar seu tempo: Tu não me enganas, mundo, e não te engano a ti, diz ele em "Legado". Assim, pode-se compreender porque Octavio Paz, ao tratar da historicidade do poema, afirma que o poeta não escapa à história, inclusive quando a nega ou ignora. Suas experiências mais secretas ou pessoais se transformam em palavras sociais, históricas (PAZ, 1996, p. 55). Se, por um lado, o poema transcende o seu tempo, por outro, se inscreve em determinada época e lugar. Como poeta-crítico, Octavio Paz é daqueles que acreditam que toda a criação poética é histórica, não importa qual seja o seu modo de manifestação, pois não teria sentido pensar a existência do poema sem a história e a comunidade que o alimentam e as quais alimenta. A expressão poética é, desse modo, a representação mais profundamente verdadeira do espírito coletivo de um povo, ao mesmo tempo que seu próprio fundamento. Sendo anterior a qualquer acontecimento datável, é um ato original que principia toda história social ou individual. É como testemunho histórico que a poesia corresponde à sociedade da qual é originária. A arte, já dizia Hegel, está sempre em paralelo com a cultura.

$\mathrm{Na}$ realidade, o poeta moderno além de abandonar a missão de grande revelador de um poder estranho tornou-se também extremamente crítico, não só de 
seu tempo, mas principalmente de sua arte. Agora lhe interessa menos revelar verdades sagradas. E uma vez que escolheu fundar a palavra poética no próprio homem, $a$ escritura poética é a revelação de si mesmo que o homem faz a si mesmo (PAZ, 1996, p. 77). Rompendo a antítese estabelecida entre sensibilidade e conhecimento, a poesia moderna, cada vez mais auto-reflexiva, mostra que razão e imaginação não são faculdades opostas: a segunda é o fundamento da primeira e o que permite perceber e julgar o homem (Ibid.). ${ }^{4}$ Isso é o mesmo que dizer, como realmente o disse Coleridge, lembrado por Octavio Paz, que a imaginação é a faculdade original de toda percepção humana, o que também faz lembrar a lição aristotélica recuperada por Vico: Nada há na inteligência que primeiramente não tenha transitado pela sensibilidade (VICO, 1979, p. 68). ${ }^{5}$ O poeta de Claro Enigma sabia muito bem disso. Era capaz de captar a idéia, através da imaginação, e mostrar em poesia a mais alta capacidade de pensar com emoção. É por isso que a força com que inscreve seus versos em nossa alma parece dizer que outro modo de ser e prosseguir seria inconcebível. Como quem, contra as mazelas do mundo, passou a vida entoando uma flor, ele resiste, procurando manter a dignidade diante da estupidez das ações humanas, sempre prontas a destruir a fluida substância de nossos segredos:

"Nossos donos temporais ainda não devassaram

o claro estoque de manhãs

que cada um traz no sangue, no vento.

Passarei a vida entoando uma flor, pois não sei cantar nem a guerra nem o amor cruel, nem os ódios organizados, e olho para os pés dos homens, e cismo.

Escultura de ar, minhas mãos

te modelam nua e abstrata

para o homem que não serei.

Ele talvez compreenda com todo corpo, para além da região minúscula do espírito, a razão de ser, o ímpeto, a confusa distribuição, em mim, de seda e péssimo". (“Contemplação no Banco", p. 32)

Em suas reflexões sobre a lírica moderna, Hugo Friedrich, por exemplo, nota que entre os poetas do século XIX, que foram os fundadores da lírica moderna, como Rimbaud e Mallarmé, e os poetas do século XX perduram alguns elementos estrutu-

${ }^{4} N$ esse sentido, ao se referir a Coleridge, Octavio Paz lembra que o poeta inglês foi um dos primeiros a debruçar-se sobre a criação poética, a fim de perguntar-lhe o que significa ou diz realmente o poema, e para quem a imaginação funciona não só como um órgão do conhecimento, mas como a faculdade de expressá-lo em símbolos e mitos. ( p.77)

${ }^{5}$ Vico parte do princípio de que, assim como os primeiros poetas ouviram acerca da sabedoria popular, também os filósofos, através desses poetas, dela tomaram conhecimento, de modo que poetas e filósofos, respectivamente, podem ser considerados o sentido e o intelecto do gênero humano. 
rais comuns. Esses elementos correspondem a uma certa obscuridade que envolve a lírica moderna, podendo-se, inclusive, falar de uma dramaticidade agressiva, que já não provém de um indivíduo em particular, mas de uma inteligência que poetiza. ${ }^{6}$ Isso não quer dizer que os sentimentos já não passem pela alma do poeta, mas sim que o estado que o anima agora é diferente daquela pura disposição de ânimo, de que fala Emil Staiger. ${ }^{7}$ Os sentimentos são então atravessados por palavras duras, fechadas, desarmoniosas, de categorias predominantemente negativas. É nisso que a lírica moderna se diferencia de forma severa da lírica precedente. Quando a lírica deixou de ser a ressonância da sociedade para colocar-se em oposição a esta sociedade, houve uma queda da aura, para lembrar Walter Benjamin, e a poesia acabou perdendo aquela ingenuidade essencial pela qual clamava Schiller. As categorias positivas de harmonia, dignidade, idealização e afeto cedem lugar a predisposição de algo que, ao mesmo tempo que fascina, tende a ser inquietante e obscuro, não raras vezes inclinandose ao Nada. A escuridão e a incoerência tornaram-se os pressupostos da sugestão lírica (1978, p.29), diz Friedrich. Nesse sentido, a poesia de Mallarmé coloca-se como um dos exemplos mais agudos do que se acabou de falar, na medida em que sua leitura algumas vezes exige um verdadeiro ato de decifração, tão alto o grau de hermeticidade em alguns de seus poemas.

Quanto à temática do nada, referindo-se a Carlos Drummond de Andrade, esta aparece de forma bem nítida em Claro Enigma e passa a ser uma matéria concreta que o poeta trata em poemas como: "Dissolução", "Contemplação no Banco", "Fraga e Sombra", "Aniversário", "Carta", "Relógio do Rosário" ou "Cantiga de Enganar". Mas o que mais inquieta nesse livro é o modo de enfrentamento da palavra provocado pela mudança de atitude do poeta mineiro, reveladora de novas e significativas preocupações acerca do fazer poético: aborrecido com o cotidiano, ele recria o tempo através da poesia, desafiador e intencionalmente obscuro em relação a composições anteriores, como se o leitor devesse ir além das páginas escritas para decifrar seu soneto duro, que de tão incomodo ninguém o lembrará:

"Eu quero compor um soneto duro como poeta algum ousara escrever. Eu quero pintar um soneto escuro, seco, abafado, difícil de ler.

(...)

Ninguém o lembrará: tiro no muro, cão mijando no caos, enquanto Arcturo, claro enigma, se deixa surpreender." ("Oficina Irritada", p.42)

A verdade é que a evolução histórica da lírica mostra que seus cultores são

${ }^{6} \mathrm{Cf}$. FRIEDRICH, 1978. É desse modo que surge, para Hugo Friedrich, a questão do motivo por que se pode descrever o poetar moderno muito mais exatamente com categorias negativas do que com positivas. É uma questão de determinação histórica desta lírica - uma questão de futuro (p.22). Nesse sentido, só o tempo pode responder a razão de tal anormalidade.

${ }^{7}$ Cf. STAIGER, 1993. 
muito mais do que seres naturalmente inspirados. Sua poesia, para além de uma expressão individual, brota dessa inteligência que poetiza, de que fala Hugo Friedrich. Entre poesia e pensamento abstrato, algumas vezes, há apenas um tênue limite. É esse limite que caracteriza o ser próprio da poesia. O sentimento, elemento tradicional da lírica, nada comunicaria sem o auxílio ordenador do pensamento racional, por isso, diz Merquior, em poesia pode-se falar de uma razão poética que é diferente da razão lógica. Mas é razão.

Como fotógrafo da alma, as imagens que o poeta cria são o retrato mais perfeito da história sensível da humanidade, por isso Octavio Paz nos diz que a poesia é a memória do povo. Dessa forma, pode-se entender sua função social, sua capacidade de unir realidades, resgatar o passado, dizer o presente e traduzir o futuro, por mais hermético que possa parecer seu modo de fazê-lo. E mais além, a poesia também cumpre uma outra função, que é a de nomear as coisas e pensar o que os discursos correntes não pensam. Para que isso fosse possível a poesia teve cada vez mais que se exilar do meio agônico em que (sobre)vive. Precisou se distanciar para melhor enxergar. ${ }^{8}$ Assim o fez Drummond em Claro Enigma, procurando, por outro lado, resgatar através da memória um tempo já vivido. Isso acontece mais profundamente nos poemas que compõem a seção Selo de Minas, onde fica bem clara a necessidade de reencontro do poeta com suas origens, depois de contra elas ter se rebelado em momentos anteriores: depois de sua negação nos buscará, diz agora uma voz familiar no poema "Os bens e o sangue". Os estragos do tempo nas almas e nas cidades, como está muito bem estampado no poema "Morte das casas de Ouro Preto", o deixam perplexo, por isso está continuamente buscando um ponto de equilíbrio entre o passado e o presente. Em si mesmo recolhe o peso desesperado do tempo que consome todas as coisas. Não só a história é remorso, como nos diz o poeta em "Museu da Inconfidência", como o tempo é uma chaga que não deixa os homens libertos de seu próprio medo.

Difícil é colocar um ponto final quando se trata de Claro Enigma, pois há muitos mais aspectos a enfatizar. Deixa-se, assim, as palavras de Valèry, ao se referir a poética de Mallarmé, que certamente dá conta do estatuto da arte de Carlos Drummond de Andrade, quando está em questão um livro como o que se acabou de referir:

"Mallarmé criava na França a noção de autor difícil. Ele introduzia na arte a obrigação do esforço intelectual. Com isso, elevava a condição do leitor; e, com admirável compreensão da verdadeira glória, escolhia na sociedade o pequeno número de amadores particulares que, depois de experimentálo, já não conseguiam suportar poetas impuros, imediatos e indefesos. Tudo lhes parecia ingênuo e tíbio depois de o terem lido."’

De qualquer maneira, se é certo que a obra de Drummond deixou rastros que

${ }^{8}$ Nesse sentido, conferir o percusciente ensaio de Alfredo Bosi, "Poesia resistência", que compõe o conjunto de ensaios de O Ser e o Tempo da Poesia, 1997, p. 139-192.

${ }^{9}$ Esse fragmento do texto de Paul Valèry foi retirado da contracapa do livro Prosas de Mallarmé. Tradução de Dorothée de Bruchard. Porto Alegre, Paraula, 1995. 
apontam para muitas direções, provocando uma diversidade de reações em seus leitores, também é certo que jamais almejou qualquer forma de catequização. Esta é a grande lição de sua poesia: a de não se pretender lição de nada, apenas comunicar o essencial sentimento do mundo. Talvez por isso não se prenda definitivamente nem mesmo aos conceitos de ordem estética. Modernista ou clássico, o poeta mineiro, naquela vertente poética inaugurada por Baudelaire, foi, antes de tudo, profunda e absolutamente moderno, senão eterno: E como ficou chato ser moderno/ agora serei eterno./ Não quero ser senão eterno.

Ler Drummond ajuda a compreender porque Hegel elegeu a poesia como a arte universal, num grau superior ao das outras artes. E faz compreender, sobretudo, porque o filósofo alemão entendia que toda verdadeira arte é essencialmente uma interrogação endereçada ao coração sensível, um apelo às mentes e aos espíritos, uma

viagem ao desconhecido, como disse Maiakóvski, um ato de fé, como queria Octavio Paz.

\section{BIBLIOGRAFIA}

ANDRADE, Carlos Drummond de. A máquina do mundo. In: Claro Enigma. Rio de Janeiro, Record, s/d.

BOSI, Alfredo. Poesia resistência. In: O Ser e o Tempo da Poesia. São Paulo, Cultrix, 1997.

CAMPOS, Haroldo de. Drummond, mestre de coisas. In: Metalinguagem \& Outras Metas. 4. ed. São Paulo, Perspectiva, 1992.

CAMPOS, Paulo Mendes. 1987 foi Drummond. In: Jornal Brasil, 27 dez. 1987, p.02.

FRANCO, Afonso Arinos de Melo. O predomínio dos atributos intelectuais. In: Carlos Drummond de Andrade. Coletânea organizada por Sônia Brayner, nota preliminar de Afrânio Coutinho. Rio de Janeiro, Civilização Brasileira; Brasília, INL, 1977.

FRIEDRICH, Hugo. Estrutura da Lírica Moderna. Traduzido por Marise M. Curione. São Paulo, Duas Cidades, 1978.

HEGEL, Georg W. F. O Belo Artístico ou o Ideal. In: Curso de Estética - O Belo na Arte. Traduzido por Orlando Vitorino e Álvaro Ribeiro. São Paulo, Martins Fontes, 1996.

LIMA, Luiz Costa. O princípio-corrosão na poesia de Carlos Drummond. In: Lira e Antilira: Mário, Drummond, Cabral. Rio de Janeiro, Civilização Brasileira, 1968.

LINS, Álvaro. Jornal de Crítica. Rio de Janeiro, O Cruzeiro, 1963.

MACHADO DE ASSIS, Joaquim Maria. Teoria do Medalhão. In: Machado de Assis: Seus trinta melhores contos. 6. ed. Rio de Janeiro, Nova Fronteira, s/d.

MERQUIOR, José Guilherme. Verso Universo em Drummond. Rio de Janeiro, José Olympio, 1975. 
. “Crítica, Razão e lírica”. In: Razão do Poema. 2.ed. Rio de Janeiro, Topbooks, 1996.

MORAES, Emanuel. As várias faces de uma poesia. In: Carlos Drummond de Andrade. Coletânea organizada por Sônia Brayner, nota preliminar de Afrânio Coutinho. Rio de Janeiro, Civilização Brasileira; Brasília, INL, 1977.

PAZ, Octavio. A consagração do instante. O verbo desencarnado. In: Signos em rotação. 3. ed. Traduzido por Sebastião Uchoa Leite. São Paulo, 1996.

STAIGER, Emil. Conceitos Fundamentais da Poética - 2.ed - Traduzido por Celeste Aída Galeão. Rio de Janeiro, Tempo Brasileiro, 1993.

TELES, Gilberto Mendonça. Drummond - A estilística da repetição. Rio de Janeiro, José Olympio, 1970.

VICO, Giambattista. Princípios de uma ciência nova. Traduzido por Antônio Lázaro de Almeida Prado. 2. ed. São Paulo, Abril Cultural, 1979. 